\title{
Growth of climate change commitments from HFC banks and emissions
}

\author{
G. J. M. Velders ${ }^{1}$, S. Solomon ${ }^{2}$, and J. S. Daniel ${ }^{3}$ \\ ${ }^{1}$ National Institute for Public Health and the Environment (RIVM), P.O. Box 1, 3720 BA Bilthoven, the Netherlands \\ ${ }^{2}$ Department of Earth, Atmospheric and Planetary Sciences, Massachusetts Institute of Technology, 77 Massachusetts \\ Avenue, Cambridge, MA 02139, USA \\ ${ }^{3}$ National Oceanic and Atmospheric Administration, Earth System Research Laboratory, Chemical Sciences Division, 325 \\ Broadway, Boulder, CO 80305, USA
}

Correspondence to: G. J. M. Velders (guus.velders@rivm.nl)

Received: 27 November 2013 - Published in Atmos. Chem. Phys. Discuss.: 16 December 2013

Revised: 19 March 2014 - Accepted: 24 March 2014 - Published: 12 May 2014

\begin{abstract}
Chlorofluorocarbons (CFCs) are the primary cause of ozone depletion, and they also contribute to global climate change. With the global phaseout of CFCs and the coming phaseout of hydrochlorofluorocarbons (HCFCs), the substitute hydrofluorocarbons (HFCs) are increasingly used. While CFCs were originally used mainly in applications such as spray cans and were released within a year after production, concern about the ozone layer led to reductions in rapidrelease applications, and the relative importance of slowerrelease applications grew. HFCs are now mainly used in refrigerators and air conditioners (AC) and are released over years to a decade after production. Their containment in such equipment represents banks, which are building up as production grows. A key finding of our work is that the increases of HFC banks represent a substantial unseen commitment to further radiative forcing of climate change also after production of the chemicals ceases. We show that earlier phaseouts of HFCs would provide greater benefits for climate protection than previously recognized, due to the avoided buildup of the banks. If, for example, HFC production were to be phased out in 2020 instead of 2050, not only could about 91-146 $\mathrm{GtCO}_{2}$-eq of cumulative emission be avoided from 2020 to 2050, but an additional bank of about $39-64 \mathrm{GtCO}_{2}$ eq could also be avoided in 2050. Choices of later phaseout dates lead to larger commitments to climate change unless growing banks of HFCs from millions of dispersed locations are collected and destroyed.
\end{abstract}

\section{Introduction}

Concern about damage to the Earth's ozone layer prompted the signing of the Montreal Protocol in 1987, an international treaty that has since been hailed as one of the most successful environmental agreements. The halocarbons that were the primary cause of ozone loss are also potent greenhouse gases (Ramanathan, 1975), and reductions in emissions of these gases have benefitted both the ozone layer and efforts to reduce anthropogenic climate change (Velders et al., 2007). At the time that the protocol was developed, chlorofluorocarbons were the primary halocarbons addressed, and most of the emissions of these gases occurred rapidly (within about a year after production), in applications such as spray cans, metered-dose medical inhalers, open-cell foams, and solvents (Fig. 1) (Fisher and Midgley, 1994; Gamlen et al., 1986). Citizen actions and national regulation already led to reductions in the use of CFCs in spray cans in some countries before the protocol was signed (Andersen and Sarma, 2002). By reducing production and consumption of rapidly released gases in each country, measures taken under the protocol quickly led to further changes in emissions of CFCs, with very little time lag. While CFC production is phased out globally, a small amount of emission of these gases continues (see Fig. 2), due mainly to release from applications where their use involves containment and storage, i.e., a bank of material. The primary banks are in refrigeration and air conditioning (AC) applications, from which gases are released on a timescale of years to about a decade (medium timescale), and 

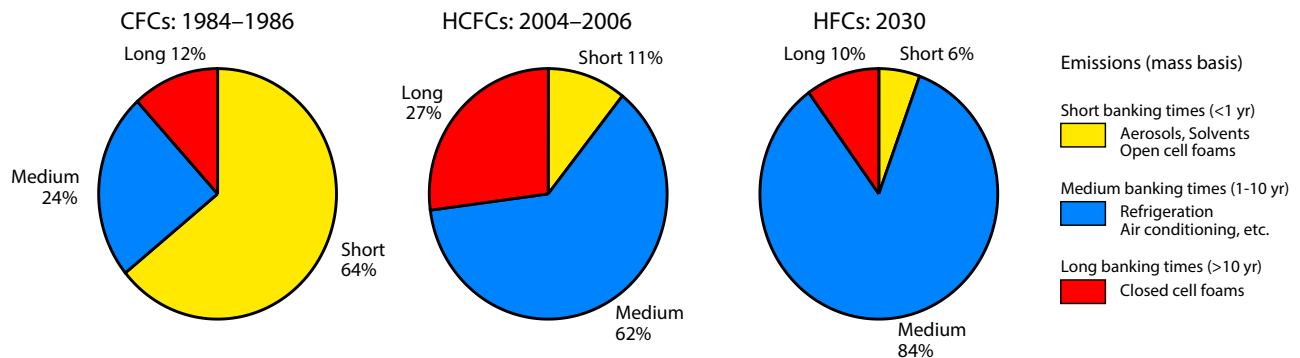

Fig. 1. Contributions of different types of applications to the emissions (mass basis) of CFCs, HCFCs, and of HFCs. The applications differ in the delay times between production and emission (banking times; see Table 1). The CFC and HCFC emissions (AFEAS, 2009) are shown for those years when they were used extensively and reductions in their emission were not affected much by Montreal Protocol regulations. HFC emissions are the average of the upper- and lower-range scenarios for 2030 from Velders et al. (2009).

in closed-cell foams, from which they are released over multiple decades (long timescale, e.g., in building insulation). This represents a legacy, or commitment, of continued environmental impact from past production of CFCs, but its magnitude is relatively small since so much use of CFCs occurred in rapid-release applications and because production for the longer timescale release applications has been in decline for over two decades.

Substitute processes and chemicals that replace the CFCs have evolved in the decades since the Montreal Protocol entered into force. Motivated by environmental concerns, many applications now employ approaches that do not require halocarbons at all, referred to here as 'not-in-kind' substitutions; an example is the widespread use of hydrocarbons rather than halocarbons in spray cans today. CFCs have also been replaced by other halocarbons. Initially, some uses of CFCs were replaced with HCFCs, which have a reduced impact on ozone, and now increasingly with HFCs, which do not deplete ozone at all. The contributions of emissions of HCFCs and HFCs to climate change depend upon their atmospheric lifetimes and radiative efficiencies and thereby on their global warming potentials (GWPs), as well as the total emission and hence the abundance. The GWP is an index comparing the integrated radiative forcing of an emission of a greenhouse gas, integrated over typically one hundred years, relative to that of emitting the same mass of carbon dioxide (see, e.g., IPCC/TEAP, 2005). Most HFCs currently used have relatively long atmospheric lifetimes (e.g., HFC134a, with a lifetime of about 13 years) and GWPs in excess of 1000, and are sometimes referred to as high-GWP HFCs. Throughout this paper, we refer to high-GWP HFCs unless otherwise noted (see Sect. 7). HCFCs are now scheduled to be phased out globally in 2040, and are already being replaced by HFCs (as well as by a lesser amount of not-in-kind materials and technologies). As a result, atmospheric HFC concentrations are rapidly growing, by $10-15 \%$ per year from 2006 to 2010 (UNEP, 2011a). The increase in concentrations implies a growing contribution of HFCs to radiative forcing of climate change, which could become substantial in comparison to carbon dioxide under some circumstances (Gschrey et al., 2011; Velders et al., 2009, 2012).

CFCs used in rapid-release applications, like spray cans and solvents, were largely replaced with not-in-kind alternatives right away after environmental concerns were recognized. Because of these same concerns, HCFCs and HFCs were always only used in limited amounts for rapid-release applications. Figure 1 shows that the substitution of CFCs with HCFCs and HFCs coincided with a shift away from rapid-release applications to applications involving containment, particularly refrigeration and AC (see also McCulloch et al., 2003). Further, environmental concerns led to tighter systems that increase the time the material spends in equipment (e.g., by the use of improved hoses that leak less in mobile AC). As a result of the shift to longer-timescale uses, each additional year of production in HCFCs and HFCs leads to an increasing buildup in banks. The unseen and growing commitment to climate change from the HFCs produced but not yet released has not been clearly discussed or quantified, and is the focus of this paper. In several previous HFC scenario studies (Velders et al., 2009, 2012; Gschrey et al., 2011; IPCC/TEAP, 2005; Meinshausen et al., 2011; UNEP, 2009a) banks have been considered in the modeling approach, but the focus in discussing climate change effects was only on emissions and radiative forcing, and the fact that the time lag between production and emissions results in a bank and associated hidden climate impacts was not discussed.

HFCs are among the basket of gases of the Kyoto Protocol. Since 2009, there have been discussions among the parties to the Montreal Protocol about including the HFCs under this protocol as well, and limiting their consumption and production to avoid a potentially large future contribution to climate change. The progression from CFCs to HFCs and the accompanying changes in banks create a new issue for policy design that poses several options: (i) doing nothing and allowing the banks to build up and be released, causing further climate change; (ii) taking steps to collect and destroy the banks as part of a phaseout schedule; or (iii) planning a phaseout schedule at an earlier time that avoids the buildup of the banks. Here we show that the benefits 

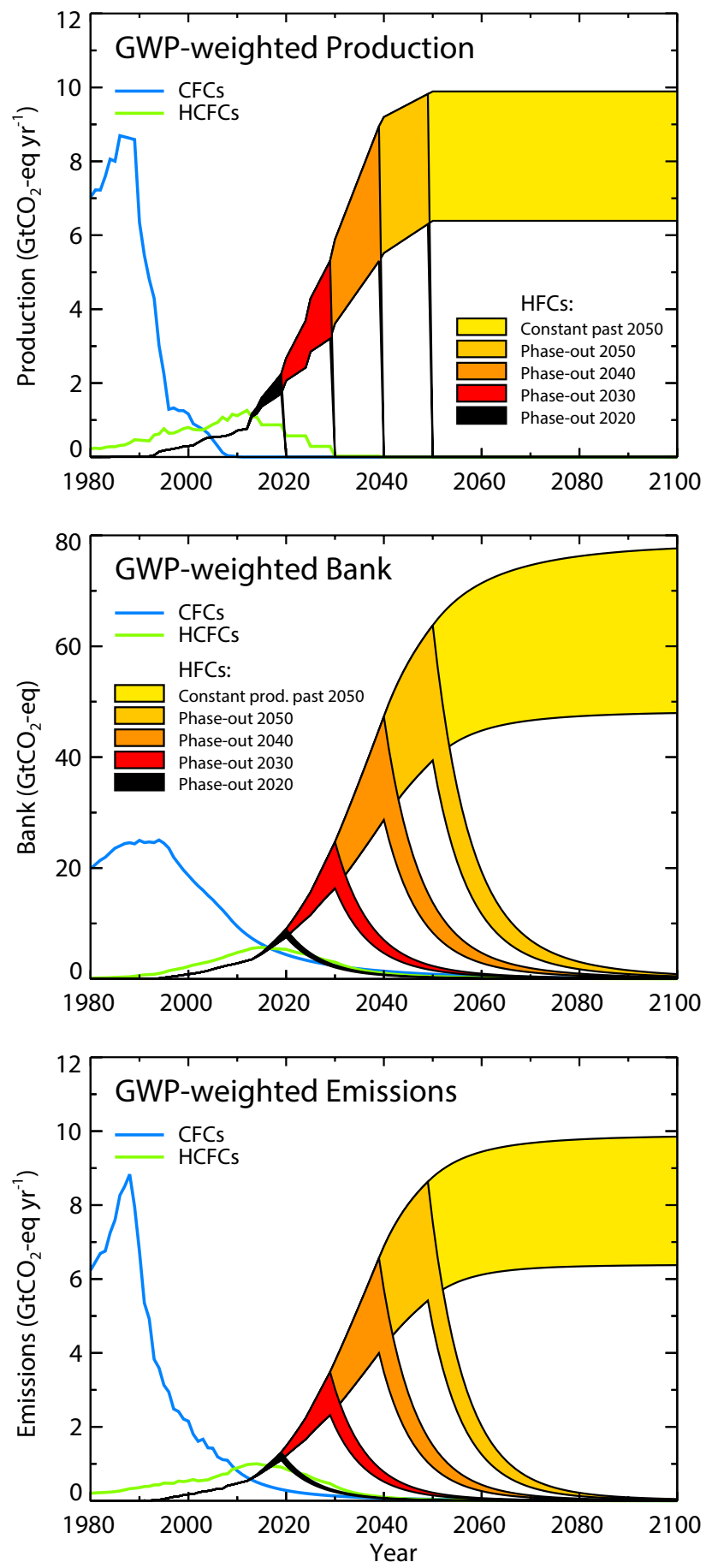

Fig. 2. GWP-weighted production, bank, and emissions of halocarbons for the period 1980 to 2100 . Calculated direct GWP-weighted data (100 yr time horizon) are shown for the baseline scenarios of the CFCs and HCFCs (WMO, 2011) and the upper and lower ranges of the HFC scenarios from Velders et al. (2009). In these scenarios the HFC production past 2050 is constant at the 2050 level. Four additional scenarios are shown in which there is a global phaseout in production of HFCs in 2020, 2030, 2040, or 2050. The GWPs used here are those used in the reference scenarios, i.e., of WMO (2011) for the CFCs and HCFCs, and IPCC (2007) for the HFCs. of earlier HFC phaseouts will be greater than previous estimates, where emissions, concentrations, and radiative forcing were considered, but not the effects of the banks remaining at the end of the period examined (UNEP, 2011a; Velders et al., 2012), since actions taken sooner will avoid the buildup of banks of these gases. Equivalent climate protection could be achieved with later phaseout dates if the banks are collected and destroyed at those times. Indeed, in some countries, banked CFCs from refrigerators and AC are already collected and destroyed. However, while production and consumption controls involve no more than a few dozen chemical manufacturers and about 200 countries, there are many millions of individual refrigeration and $\mathrm{AC}$ units, making later recovery and destruction a more complex option than reducing production. Below we evaluate the relevant bank sizes and climate impacts that would be associated with different HFC phaseout dates, as well as the benefits in terms of both emissions and banks obtained through earlier phaseouts.

\section{Applications of halocarbons}

In Table 1 the applications of the specific CFCs, HCFCs, and HFCs illustrated in Fig. 1 are listed and grouped according to the delay times (banking times) between production and emission. About $64 \%$ of CFC emission in the period just before the Montreal Protocol was signed came from applications with short banking times, such as aerosol propellants, cleaning agents, and open-cell foams (Fig. 1). In addition, extensive emissive use as solvents occurred at that time for two additional ozone-depleting gases, methyl chloroform and carbon tetrachloride. Emissive applications made up about $11 \%$ of HCFC emissions in the middle of the last decade, during which they were extensively used, and are projected to make up about $6 \%$ of the HFC emissions in coming decades based on calculations from Velders et al. (2009). The HFC emissions in the scenario of Gschrey et al. (2011) show a very similar mix of applications with short (about 5\%), medium (about 89\%), and long (about $6 \%$ ) banking times, although their total emission levels are about half the levels of the scenario of Velders et al. (2009) in 2050 .

\section{Scenarios of halocarbons}

The CFC and HCFC scenarios used here are identical to the baseline scenario from WMO (2011). These scenarios apply the following constraints: (i) observed mixing ratios to estimate historical annual average emissions (top-down); (ii) bottom-up bank estimates by UNEP (2009a), if available, for the year 2008; (iii) reported production of halocarbons from UNEP (2010); and (iv) phaseout schedules of the Montreal Protocol; see Velders and Daniel (2014) for a more extensive description. The bottom-up bank estimates for 2008 are based on inventories of the number of units of equipment 
Table 1. Main applications of CFCs up to about 1990 and of HCFCs and HFCs currently.

\begin{tabular}{lccc}
\hline Applications & CFCs & HCFCs & HFCs \\
\hline \multirow{2}{*}{ Aerosol propellant } & Short banking times $(<1$ years $)$ & \\
& CFC-11 & & HFC-134a \\
Cleaning agent (solvent) & CFC-12 & & HFC-152a \\
& CFC-113 & HFC-227ea \\
Open-cell foam blowing & CFC-113 & HCFC-225ca & \\
& & HCFC-225cb & \\
& CFC-11 & HCFC-141b & HFC-134a \\
& CFC-113 & HCFC-142b & HFC-152a \\
\hline
\end{tabular}

\begin{tabular}{|c|c|c|c|}
\hline \multicolumn{4}{|c|}{ Medium banking times ( 1 to $10 \mathrm{y}$ ) } \\
\hline \multirow[t]{5}{*}{ Refrigeration and stationary air conditioning } & CFC-11 & HCFC-22 & HFC-23 1,2 \\
\hline & CFC-12 & & HFC- $32^{1}$ \\
\hline & CFC-114 & & HFC- $125^{1}$ \\
\hline & CFC-115 & & HFC- $134 \mathrm{a}^{1}$ \\
\hline & & & HFC- $143 \mathrm{a}^{1}$ \\
\hline Mobile air conditioning & CFC-12 & & HFC-134a \\
\hline \multirow{3}{*}{ Fire extinguishing } & & HCFC-123 & HFC-23 \\
\hline & & & HFC-125 \\
\hline & & & HFC-227ea \\
\hline \multicolumn{4}{|c|}{ Long banking times ( $<10$ years) } \\
\hline \multirow[t]{3}{*}{ Closed-cell foam blowing } & CFC-11 & HCFC-141b & HFC-134a \\
\hline & CFC-12 & HCFC-142b & HFC-245fa \\
\hline & & HCFC-22 & HFC-365mfc \\
\hline
\end{tabular}

containing CFCs and HCFCs and the amount of halocarbons present in the equipment. In other years, the bank at the start of a particular year is equal to the sum of the bank in the previous year and production from that year, with the emission from that year subtracted. Historical bank sizes could also be estimated from solely historic production data and top-downderived emission, but banks derived this way have larger and unknown uncertainties, because they are the result of an accumulating difference between two numbers (Daniel et al., 2007). Emission factors, which represent the fraction of the total bank of specific ozone-depleting substances (ODSs) that are released each year, are derived from the ratio of the top-down-derived emissions and the bank estimates over the period 1999 to 2008, and are used to calculate the depletion of the bank and annual emissions past 2008. These emission factors are overall factors applied to the total bank of a specific ODS. Possible future changes in these factors are not taken into account in the scenario. But such changes are probably small for all CFCs and HCFCs, since currently most individual CFCs and HCFCs are emitted from a single type of application. For example, CFC-11 is currently emitted al- most completely from closed-cell foams, while CFC-12 is emitted from stationary refrigeration and AC.

The HFC scenarios used in this study are the upper- and lower-range scenarios of Velders et al. (2009). These scenarios can be characterized as business-as-usual scenarios in the sense that they assume that the current patterns of replacement of CFCs and HCFCs with particular HFCs and other substances and technologies, as observed in the past few years in developed countries, continue unchanged and will also apply to developing countries. These scenarios do not consider global regulations of technological developments on the use and emissions of HFCs, nor do they incorporate changing market conditions since 2009. They project the demand and emissions of HFCs for developed and developing countries based on growth in population and economy from 2010 to 2050 (IPCC, 2000). The demand in developed countries is assumed to be proportional to the projected growth in population, and the demand in developing countries is proportional to the growth in gross domestic product (GDP). The per capita HFC demand in developing countries is limited to the per capita demand in developed countries, and is determined for each type of application. The HFC demand past 
2050 is fully saturated; i.e., the demand up to 2100 is kept constant at the 2050 level (see also Xu et al., 2013). Annual emissions are calculated as a constant fraction of the bank. These fractions (emission factors) for most HFCs are based on the fractions observed for the HCFCs they replace.

The mix of chemicals and technologies that will be used to replace the HCFCs are key to the HFC emissions in these scenarios since the HCFCs are scheduled to be phased out globally by 2040 following the regulations of the Montreal Protocol. In the scenarios (Velders et al., 2009), $90 \%$ of the HCFC use in refrigeration and stationary AC applications is assumed to be replaced with blends of HFC-32, HFC-125, HFC-134a, and HFC-143a while $10 \%$ is assumed to use notin-kind technologies or chemicals. Half of the HCFC use in foams is replaced with HFC-134a, HFC-245fa, and HFC$365 \mathrm{mfc}$, while the other half is replaced with not-in-kind technologies or chemicals. A small demand for HFC-152a for specialty industrial aerosols is continued in the scenarios. The phaseout of HFC-134a for mobile AC in Europe in 2017 is included in the scenario, while in other regions the use of HFC-134a is continued unabated. In the scenarios this mix of HFCs and not-in-kind alternatives remains constant for the whole time period considered.

The magnitude of future production and demand are important for our calculations; an under- or overestimation of them will also give an under- or overestimation of the future size of the banks. These scenarios of Velders et al. (2009), with their projections of production, banks, and emissions of HFCs, are at the upper range of published HFC scenarios. Other scenarios differ because they assume different and/or temporally changing replacement patterns of HCFCs with HFCs and not-in-kind technologies, and different growth rates for the demand and market saturation (Gschrey et al., 2011). However, because the Gschrey et al. (2011) scenarios display a similar mix of short, medium, and long banking time applications to those of the reference scenario of Velders et al. (2009), the relative role of the banks as a fraction of emissions and radiative forcing in those scenarios would be similar to that displayed here, albeit with smaller absolute values for banks, emissions, and radiative forcing. Some other scenarios, such as several of the Representative Concentration Pathways (RCPs) (Meinshausen et al., 2011) also include strong mitigation actions in line with actions on other greenhouse gases. However, for the RCP scenarios, information on banks is not available; only emissions, mixing ratios, and radiative forcings have been reported.

The Multilateral Fund of the Montreal Protocol is currently funding projects in developing countries to meet their 2015 target in the HCFC phaseout. In 2015, the HCFC use in developing countries may not exceed $90 \%$ of the average 2009-2010 use. Almost all the projects currently proposed deal with the use of HCFCs for foams. In the HFC scenarios of Velders et al. (2009) and Gschrey et al. (2011) the projected emissions of HFC for foams are much smaller than the use for refrigeration and $\mathrm{AC}$ applications (see the $10 \%$ contribution of the applications with long banking times in Fig. 1), so uncertainties in these applications' replacements are not critical to our calculations.

Besides the reference scenarios, two HFC reduction scenario sets are analyzed relative to each reference scenario. In the first set of hypothetical scenarios, the production of HFCs is immediately phased out in 2020, 2030, 2040, or 2050, while in the second scenario set the banks of HFCs are collected and destroyed in 2020,2030, 2040, or 2050 on top of the production phaseout. These changes are abrupt rather than gradual and are intended as illustrative; they do not include economic considerations. Taken together, this set of scenarios illustrates the climate benefits that could be achieved with earlier production phaseouts, the effects that doing nothing would have, and sizes of the banks that may need to be collected and destroyed at later times should the parties deem that to be the preferred option.

\section{GWP-weighted production, emissions, and banks}

The potential climate effects of the transition from using CFCs to HCFCs and HFCs is shown in Fig. 2 in terms of $\mathrm{CO}_{2}$-equivalent $\left(\mathrm{CO}_{2}\right.$-eq) production, emissions, and bank sizes, using GWPs with a $100 \mathrm{yr}$ time horizon. $\mathrm{CO}_{2}$-eq is used as a simplified climate metric to compare different quantities in terms of their integrated radiative forcing over this time horizon. However, it is important to recognize that even for two emission scenarios of identical $\mathrm{CO}_{2}$-eq, if the emitted gases have different lifetimes, the effects on climate will be different at different times (Myhre and Shindell, 2013). For example, in the case of identical $\mathrm{CO}_{2}$-eq emissions, the shorter lifetimes of HFCs (compared with the atmospheric residence time of $\mathrm{CO}_{2}$ ) will result in a faster and larger short-term climate response to radiative forcing changes (e.g., on a 20-year time horizon) after HFC emissions than the much longer and nearly irreversible response after $\mathrm{CO}_{2}$ emissions (Solomon et al., 2009). The projected maximum GWP-weighted HFC production in 2050 is about equal to the maximum CFC production in the 1980s, while the maximum HCFC production is much less, consistent with these being largely used as transition compounds. The differences in maximum production of these halocarbons are in part due to differences in GWPs of the halocarbons, but are also the result of the use of not-in-kind (non-halocarbon) substitutes, especially for CFCs (McFarland, 1999). The large values for the HFCs in 2050 are mainly caused by growth (particularly of GDP in the developing world) in the longterm projections. Like other issues around sustainability, as the developing world continues to develop, demand for industrial products is likely to increase rapidly.

The GWP-weighted emissions of HFCs show a very similar behavior to the growth of CFCs before the late 1980s, but the buildup of the banks is quite different (Fig. 2 and Table 2). The CFC banks peaked at about $25 \mathrm{GtCO}_{2}$-eq around 1990 , 
Table 2. Emissions and banks of CFCs, HCFCs, and HFCs, and emissions of $\mathrm{CO}_{2}$.

\begin{tabular}{llllll}
\hline \multicolumn{5}{c}{ Halocarbons $^{1}$} \\
\hline & Year (x) & $\begin{array}{l}\text { Emission } \\
\left(\mathrm{GtCO}_{2} \text {-eq yr }^{-1}\right)\end{array}$ & $\begin{array}{l}\text { Cumulative emission } \\
(1950 \text { to x })\left(\mathrm{GtCO}_{2} \text {-eq }\right)\end{array}$ & $\begin{array}{l}\text { Bank } \\
\left(\mathrm{GtCO}_{2} \text {-eq }\right)\end{array}$ & $\begin{array}{l}\mathrm{CO}_{2} \text { emission }^{2} \\
\left(\mathrm{GtCO}_{2} \text {-eq yr }^{-1}\right)\end{array}$ \\
\hline CFCs & $1988^{3}$ & 8.8 & $154^{4}$ & 24.6 & 22 \\
HCFCs & $2014^{3}$ & 1.0 & 19 & 5.6 & $32-37$ \\
HFCs & 2020 & $1.2-1.5$ & $11-12$ & $7.5-9.0$ & $33-42$ \\
& 2030 & $2.5-3.8$ & $29-36$ & $16-25$ & $26-51$ \\
& 2040 & $4.2-6.9$ & $61-87$ & $29-47$ & $16-62$ \\
& 2050 & $5.5-8.8$ & $109-166$ & $39-64$ & $12-74$ \\
\hline
\end{tabular}

1 The CFC and HCFC emissions and banks are from the baseline scenarios (WMO, 2011). The HFC emissions and banks are the upper and lower ranges of the scenarios of Velders et al. (2009).

2 The $\mathrm{CO}_{2}$ emissions are from fossil and industrial uses. The ranges are from the upper and lower RCP scenarios (Meinshausen et al., 2011).

3 Years with maximum emissions in the baseline scenario.

4 The cumulative CFC emissions from 1950 to 2014 are $226 \mathrm{GtCO}_{2}$-eq.

while the HFC banks are projected to have the potential to reach more than twice this size, about $50-80 \mathrm{GtCO}_{2}$-eq, at the end of the 21th century. This is another illustration of the impact of HFCs being used largely in slower-release applications, in contrast to CFCs (see also Fig. S1, Supplement).

Table 2 shows that in the year of maximum CFC GWPweighted emissions, i.e., 1988, the bank was about 2.8 times the annual emission, while in 2014 when HCFC emissions are projected to peak, the HCFC bank is about 5.6 times the annual emission. This ratio is even larger for the projected HFC emissions, greater than 6 in 2030 and 7 in 2050.

The GWP-weighted halocarbon banks and emissions shown in Fig. 2 and Table 2 are significant for climate change when compared to the historic and projected $\mathrm{CO}_{2}$ emissions. The CFC annual GWP-weighted emissions were about $40 \%$ of the annual $\mathrm{CO}_{2}$ emissions in 1988, while the $\mathrm{CFC}$ bank in that year was slightly larger than the annual $\mathrm{CO}_{2}$ emissions, implying that another year's worth of $\mathrm{CO}_{2}$-eq emission remained in the bank at that time. The annual HFC emissions in our scenarios reach up to $12 \%$ of the upper-range annual $\mathrm{CO}_{2}$ emissions (RCP8.5) in 2050 and $75 \%$ for the $\mathrm{CO}_{2}$ scenario with strong mitigation (RCP3PD). In these scenarios, the HFC bank grows to $39-64 \mathrm{GtCO}_{2}$-eq compared with an annual $\mathrm{CO}_{2}$ emission of $12-74 \mathrm{GtCO}_{2}$-eq yr ${ }^{-1}$ in 2050 (Table 2). So, the estimated HFC bank sizes range from a factor of less than 1 to more than 5 year's worth of $\mathrm{CO}_{2}$-eq emissions in 2050 for the scenarios compared here.

The effects of possible phaseouts of HFC production in certain years are also shown in Fig. 2. The figure shows the continuing emissions that would occur after a phaseout if the banks are not destroyed: after a production phaseout, the banks decline slowly over about 20 years, as the HFCs are emitted during this period. Because of the consistently increasing HFC production through 2050, the earlier the phaseout, the shorter is the period the banks can build up and the smaller is the final bank size at the phaseout date. If, for example, the HFC production were to be phased out in 2020 instead of 2050, the cumulative emissions avoided would be about $91-146 \mathrm{GtCO}_{2}$-eq from 2020 to 2050 , while a bank of about $39-64 \mathrm{GtCO}_{2}$-eq is also avoided in 2050 , an additional benefit to climate protection of about $40 \%$ compared with the cumulative emissions reduction alone. This comparison exemplifies how an analysis that, for example, just examines emissions and radiative forcing time series through 2050 would understate the full climate benefits of an earlier HFC production phaseout.

Figure 3 presents cumulative production, emission, and banks versus time for the scenarios. Figure 3 can be compared to Fig. 2, and helps to show what is gained by the avoided banks (as compared to consideration of emissions and concentrations only) for any choice of phaseout time desired. The arrows on the figure show, for example, how a phaseout 10 years earlier than 2050 corresponds with 60$96 \mathrm{GtCO}_{2}$-eq of avoided production, of which $50-80 \mathrm{GtCO}_{2}-$ eq is manifested in avoided emission and $10-16 \mathrm{GtCO}_{2}$-eq in a smaller bank.

\section{Radiative forcing}

The contribution of halocarbons to radiative forcing of climate change depends on the product of the global average concentrations and the radiative efficiencies (generally given as radiative forcing per ppt). The radiative forcings of the halocarbon scenarios considered here are shown in Fig. 4 and Table S1 (see Supplement). The radiative forcing of the CFCs peaked around 2000 and slowly decreased since then, while that of the HCFCs is projected to peak just after 2020. In the business-as-usual scenarios, the radiative forcing of the HFCs is projected to continue increasing throughout the 21th century, and may reach values of more than $0.5 \mathrm{~W} \mathrm{~m}^{-2}$.

Figure 4 also shows the effects of HFC phaseouts at various times on radiative forcing. While the HFC emissions continue for about 20 years after a production phaseout due 

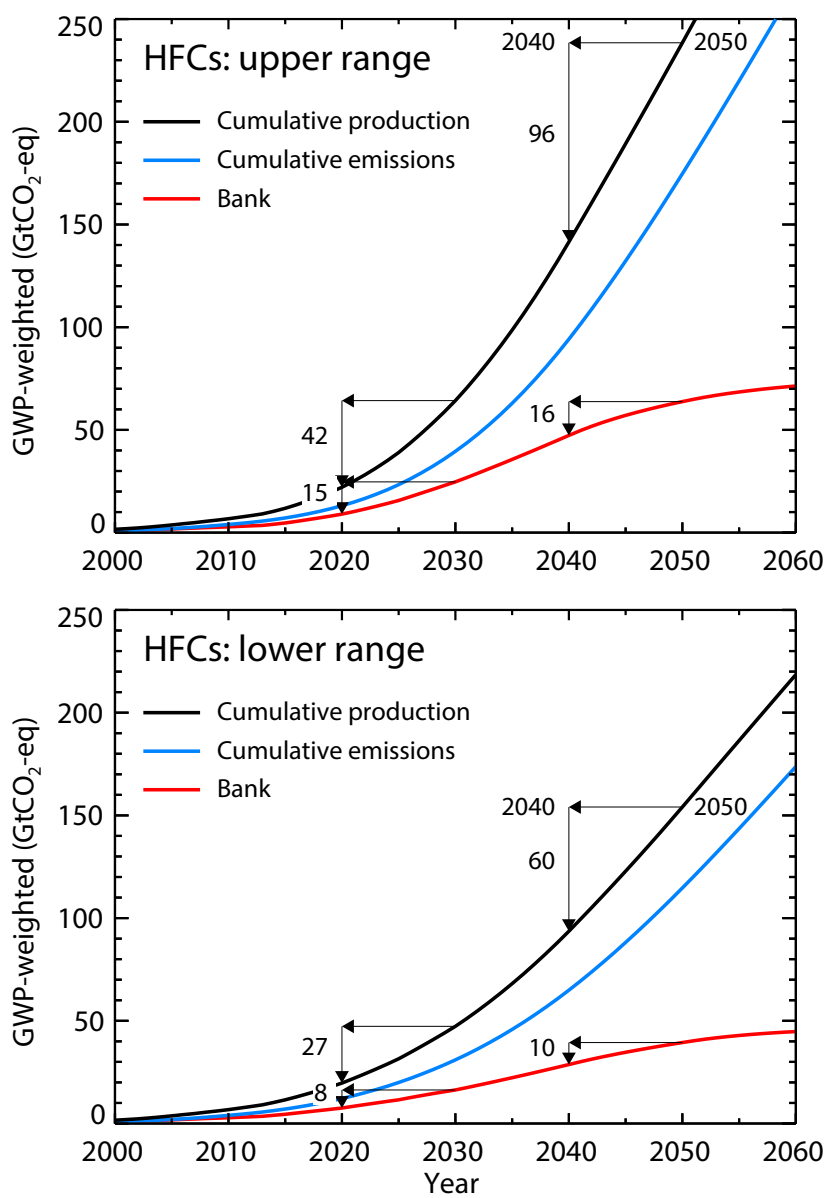

Fig. 3. Cumulative GWP-weighted production and emission and instantaneous GWP-weighted bank of the HFC upper- and lowerrange scenarios from Velders et al. (2009). The cumulative production equals the sum of the cumulative emission and the instantaneous bank. The arrows illustrate two examples of the climate benefits of an earlier phaseout in terms of both avoided emissions and reduced banks.

to emission from the banks if they are not destroyed as noted above, the HFCs continue to contribute to radiative forcing for a further several decades, as the gases are slowly removed from the atmosphere by natural processes. For example, with an HFC production phaseout in 2050, the radiative forcing decreases slowly from a maximum of $0.26-0.42 \mathrm{~W} \mathrm{~m}^{-2}$ in 2054 to $0.07-0.11 \mathrm{~W} \mathrm{~m}^{-2}$ in 2100 . However, this is still more than $0.4 \mathrm{~W} \mathrm{~m}^{-2}$ less than the forcing in 2100 in the scenario of constant production after 2050. At their peak, these radiative forcings are about $8-14 \%$ of the $\mathrm{CO}_{2}$ forcing from the mid-range of RCP scenarios (RCP4.5 and RCP6) (Meinshausen et al., 2011) (Fig. 4). While the absolute forcing is important in determining the total amount of warming since pre-industrial times, the rate of increase in forcing is important in determining the rate of transient temperature rise. The rate of increase in radiative forcing by HFCs in the reference scenario is $0.010-0.017 \mathrm{~W} \mathrm{~m}^{-2} \mathrm{yr}^{-1}$ in 2050 , which

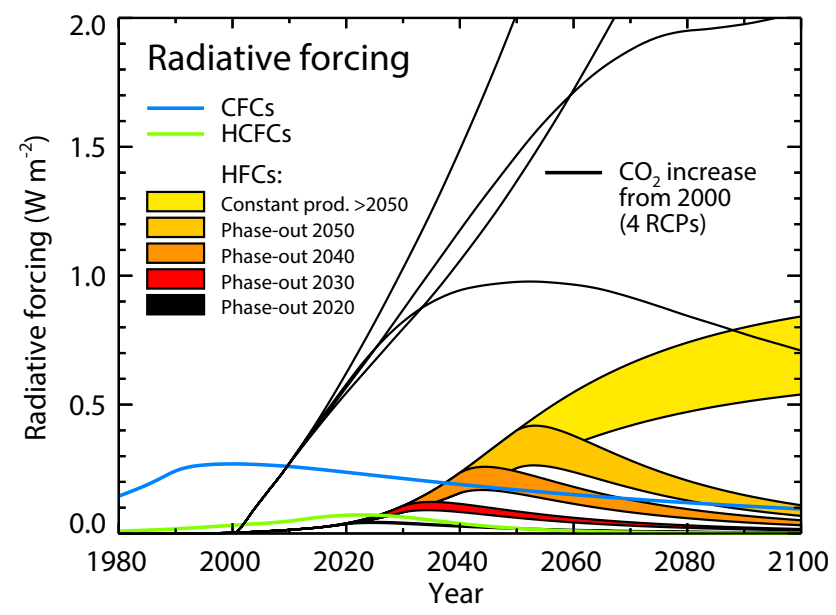

Fig. 4. Radiative forcing of halocarbons for the period 1980 to 2100 and increase in $\mathrm{CO}_{2}$ radiative forcing from 2000. The radiative forcings of halocarbons are shown for the baseline scenarios of the CFCs and HCFCs from WMO (2011) and the upper and lower ranges of the HFC scenarios from Velders et al. (2009). In these scenarios the HFC production past 2050 is constant at the 2050 level. Four additional scenarios are shown in which there is a global production phaseout of HFCs in 2020, 2030, 2040, or 2050, as in Fig. 2. No bank destruction is assumed. For $\mathrm{CO}_{2}$ the radiative increases relative to 2000 are shown for the four RCP scenarios (Meinshausen et al., 2011). The radiative forcing values for the halocarbons represent net changes from the start of the industrial era (ca. 1750) to present.

is about half the rate of increase in $\mathrm{CO}_{2}$ forcing of 0.025 $0.035 \mathrm{~W} \mathrm{~m}^{-2} \mathrm{yr}^{-1}$ in 2050 in the mid-range RCP scenarios, illustrating how large the HFC contribution could become compared to other forcing agents if there are no controls.

With a HFC phaseout in 2020, a significant bank and accumulation in the atmosphere would be avoided. Their contribution to radiative forcing then always remains small, and in 2050 it is smaller than the current forcing of HFCs of about $0.02 \mathrm{~W} \mathrm{~m}^{-2}$ (Velders et al., 2012).

\section{Committed climate forcing of HFC banks}

The buildup of the HFC banks is shown in Fig. 2, and the HFC contribution to radiative forcing is depicted in Fig. 4 for the reference scenarios and scenarios with a phaseout in production. The potential additional effects of collection and destruction of the HFC banks on reductions in radiative forcing are further illustrated in Fig. 5 and Table S1. The effect of destroying the bank is initially zero, and increases almost immediately, as some of the banks would have been released, and then decreases rapidly. If the banks are not destroyed, the HFCs would be emitted from them in about decade, and the corresponding contribution to the atmospheric abundance would decrease according to the lifetimes of the HFCs. For example, if the bank is allowed to 


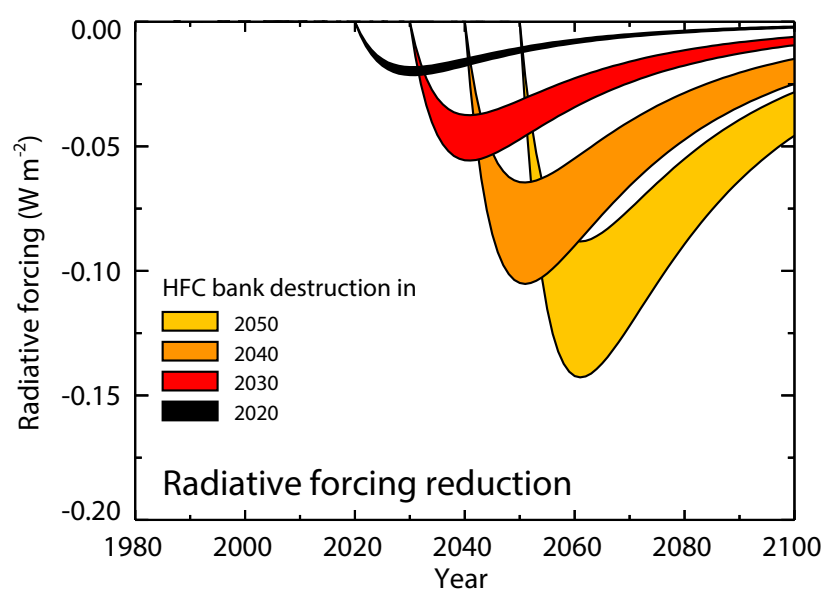

Fig. 5. Reductions in radiative forcing from destruction of the HFC banks in 2020,2030, 2040, or 2050 relative to the case with only a production phaseout in that same year. This is equivalent to the radiative forcing contribution from the HFC bank post-2020, -2030, -2040 , and -2050 in the production-phaseout scenarios. This reduction plus the production phaseout gives the maximum possible mitigation, i.e., the zero emissions scenario. The ranges correspond to the upper and lower HFC reference scenarios from Velders et al. (2009).

grow unabated until 2050, then it reaches 39-64 $\mathrm{GtCO}_{2}$-eq in our baseline scenarios. If destroyed instantaneously in 2050 , the radiative forcing is reduced by $0.09-0.14 \mathrm{~W} \mathrm{~m}^{-2}$ around 2060 and $0.03-0.05 \mathrm{~W} \mathrm{~m}^{-2}$ in 2100 , relative to the scenario in which the HFCs are gradually emitted from the bank but in which production is eliminated. It is evident that in a scenario in which the bank destruction starts earlier, the size of the banks is smaller, as is the effect of the destruction on the radiative forcing. These reductions in radiative forcing can also be viewed as the radiative forcing that arises from the post-2020, post-2030, post-2040, and post-2050 banks if the banks were not collected and destroyed, relative to the scenarios with only a production phaseout in the same years.

Figures 4 and 5 show that the maximum reduction in radiative forcing is obtained with both a production phaseout and collection and destruction of the bank. In a hypothetical scenario where a production phaseout and bank destruction occur in 2050, the radiative forcing decrease from 2050 to 2070 is $0.15-0.24 \mathrm{~W} \mathrm{~m}^{-2}$, with equal contributions from the production phaseout and bank destruction. By 2100 , the radiative forcing reduces to $0.04-0.06 \mathrm{~W} \mathrm{~m}^{-2}$, with the production phaseout contributing most of the change, about $0.19-0.29 \mathrm{~W} \mathrm{~m}^{-2}$, and the bank destruction only $0.03-$ $0.05 \mathrm{~W} \mathrm{~m}^{-2}$. The relatively greater importance of the production phaseout by 2100 occurs because once production is eliminated in 2050, most of the HFCs that originated from the 2050 bank have been destroyed by natural processes in the atmosphere. Without additional production from 2050 on, nothing further gets added to the bank after that time.
The effects on the radiative forcing of the production phaseout and bank destruction would be smaller when using other scenarios that have lower future HFC emissions as a reference (Gschrey et al., 2011; Meinshausen et al., 2011), but the previously unseen importance of the future bank can be expected to be similar in a relative sense when compared with cumulative production.

\section{Montreal Protocol}

The Montreal Protocol has controlled production and consumption of ODSs. The amounts of ODSs present in banks have not been regulated under the protocol. Controlling production and consumption was easier to carry out, and it addressed key environmental effects when most of the use was emissive, so that what was produced/consumed in a given year was also emitted in the same year. We have shown here that this not true anymore for the HFCs now used as alternatives for ODSs, because the relevant applications are much less emissive and banks that persist for years are significant and will become larger if production continues. This implies new issues and considerations for policymakers if they want to control HFCs using the expertise and the institutions of the Montreal Protocol, as agreed by the more than 100 countries that signed the Bali Declaration in 2011 (UNEP, 2011b).

Earlier phaseouts of HFCs would yield benefits for climate protection that are significantly larger, about $40 \%$ in terms of GWP-weighted emissions, than estimates based on concentrations and radiative forcing in 2050 alone, due to the added impact of avoided banks. Options to reduce the use of highGWP HFCs are available for several sectors (UNEP, 2011a, 2013) and include fiber insulation materials. Non-HFC substances with low GWPs - such as hydrocarbons, ammonia, and $\mathrm{CO}_{2}-$ are used in some refrigeration systems. Alternative HFCs with atmospheric lifetimes on the order of days or weeks, and consequently very low GWPs, are now being introduced for foams and aerosols (e.g., HFC-1234ze) and mobile AC (e.g., HFC-1234yf). In the selection of possible alternative substances and or technologies for high-GWP HFCs, the indirect climate effects that arise from the energy used or saved during the application or product's full life cycle need to be considered. Policymakers could also choose to limit future emissions of HFCs by collection and destruction of banks. In that case, the accessibility of the banks is important. Halocarbons in foams are harder and more costly to collect and destroy than those present in refrigeration and $\mathrm{AC}$ applications (UNEP, 2009b), but foams make up only a small fraction (10-15\%) of the total projected HFC bank. Also, it should be noted that the HFC banks are dispersed across the globe to a much greater extent than are the HFC production facilities, affecting the relative ease of adopting a capture and destruction approach. 


\section{Conclusion}

The Montreal Protocol entered into force in the late 1980s, when most of the regulated chlorofluorocarbon (CFC) use occurred in rapid-release applications such as spray cans, while current uses of the hydrofluorocarbon (HFC) substitutes for CFCs have shifted to applications where the gases are contained for years, or banked, such as in refrigeration and air conditioning equipment or insulation foams. We have shown that this transition has previously unrecognized policy implications. The buildup of HFC banks represents an unseen commitment to further climate change, also after production of the chemicals ends, unless the banks are collected and destroyed. We have shown that earlier phaseouts of HFCs would provide greater benefits for climate change (by as much as $40 \%$ ) than suggested by previous estimates, because of reduction of the banks.

\section{Supplementary material related to this article is available online at http://www.atmos-chem-phys.net/14/ 4563/2014/acp-14-4563-2014-supplement.pdf.}

Acknowledgements. We thank A. R. Ravishankara for helpful discussions.

Edited by: D. Shindell

\section{References}

AFEAS: Production, sales and atmospheric release of fluorocarbons through 2006. Alternative Fluorocarbons Environmental Acceptability Study, http://www.afeas.org (last access: February 2009), Arlington, VA, USA, 2009.

Andersen, S. O. and Sarma, K. M.: Protecting the Ozone layer: The United Nations History, Earthscan Press, London, UK, 513 pp., 2002.

Daniel, J. S., Velders, G. J. M., Solomon, S., McFarland, M., and Montzka, S. A.: Present and future sources and emissions of halocarbons: Towards new constraints, J. Geophys. Res., 112, D02301, doi:10.1029/2006JD007275, 2007.

Fisher, D. A. and Midgley, P. M.: Uncertainties in the calculation of atmospheric releases of chlorofluorocarbons, J. Geophys. Res., 99, 16643-16650, 1994.

Gamlen, P. H., Lane, B. C., Midgley, P. M., and Steed, J. M.: The Production and Release to the Atmosphere of $\mathrm{CCl} 3 \mathrm{~F}$ and $\mathrm{CCl} 2 \mathrm{~F} 2$ (Chlorofluorocarbons CFC 11 and CFC 12), Atmos. Environ., 20, 1077-1085, 1986.

Gschrey, B., Schwarz, W., Elsner, C., and Engelhardt, R.: High increase of global F-gas emissions until 2050, Greenhouse Gas Measurement \& Management, 1, 85-92, doi:10.1080/20430779.2011.579352, 2011

IPCC: Special report on emissions scenarios, edited by: Nakicenovic, N., and Swart, S., Cambridge Univ Press, Cambridge, UK and New York, 750 pp., 2000.
IPCC: Climate Change 2007: The physical science basis, edited by: Solomon, S., Qin, D., Manning, M., Chen, Z., Marquis, M., Averyt, K. B., Tignor, M., and Miller, H. L., Cambridge Univ Press, Cambridge, UK and New York, 996 pp., 2007.

IPCC/TEAP: Special report: Safeguarding the ozone layer and the global climate system: Issues related to hydrofluorocarbons and perfluorocarbons, edited by: Metz, B., Kuijpers, L., Solomon, S., Andersen, S. O., Davidson, O., Pons, J., de Jager, D., T., K., Manning, M., and Meyer, L., Cambridge Univ Press, New York, 478 pp., 2005.

McCulloch, A., Midgley, P. M., and Ashford, P.: Releases of refrigerant gases (CFC-12, HCFC-22 and HFC-134a) to the atmosphere, Atmos. Environ., 37, 889-902, 2003.

McFarland, M.: Applications and Emissions of Fluorocarbon Gases: Past, Present and Prospects for the Future, Non- $\mathrm{CO}_{2}$ greenhouse gases, edited by: Van Ham, J., Baede, A. P. M., Meyer, L. A., and Ybema, R., Kluwer Acad. Publ., Dordrecht, Boston and London, UK, 604 pp., 1999.

Meinshausen, M., Smith, S. J., Calvin, K., Daniel, J. S., Kainuma, M. L. T., Lamarque, J.-F., Matsumoto, K., Montzka, S. A., Raper, S. C. B., Riahi, K., Thomson, A., Velders, G. J. M., and van Vuuren, D. P.: The RCP greenhouse gas concentrations and their extensions from 1765 to 2300 , Clim. Change, 109, 213-241, doi:10.1007/s10584-011-0156-z, 2011.

Myhre, G. and Shindell, D. (coordinating lead authors), Bréon, F. M., Collins, W., Fuglestvedt, J., Huang, J., Koch, D., Lamarque, J.-F., Lee, D., Mendoza, B., Nakajima, T., Robock, A., Stephens, G., Takemura, T., and Zhang, H.: Anthropogenic and natural radiative forcing. Chapter 8 of Climate Change 2013: The physical science basis, Intergovernmental Panel on Climate Change, Cambridge Univ Press, Cambridge, UK and New York, 2013.

Ramanathan, V.: Greenhouse effect due to chlorofluorocarbons: Climate implications, Science, 190, 50-51, 1975.

Solomon, S., Plattner, G.-K., Knutti, R., and Friedlingstein, P.: Irreversible climate change due to carbon dioxide emissions, Proc. Nat. Acad. Sci., 106, 1704-1709, doi:10.1073/pnas.0812721106, 2009.

UNEP: Task force decision XX/8 report, Assessment of alternatives to HCFCs and HFCs and update of the TEAP 2005 supplement report data, United Nations Environment Programme, Nairobi, Kenya, 2009a.

UNEP: Technology and Economic Assessment Panel, Task force decision XX/7, Phase 2 report, Environmentally sound management of banks of ozone-depleting substances, United Nations Environment Programme, Nairobi, Kenya, 2009b.

UNEP: Production and consumption of ozone depleting substances under the Montreal Protocol, http://www.unep.org/ozone (last access: February 2010), United Nations Environment Programme, Nairobi, Kenya, 2010.

UNEP: HFCs: A critical link in protecting climate and the ozone layer, United Nations Environment Programme, Nairobi, Kenya, 36 pp., 2011a.

UNEP: Report of the 23th meeting of the Parties to the Montreal Protocol. Decision XXIII/IX: Annex IX: Bali Declaration, United Nations Environment Programme, Nairobi, Kenya, 2011b.

UNEP: Report of the Technology and Economic Assessment Panel, volume 2, Decision XXIV/7 Task force report, Additional infor- 
mation to alternatives on ODS, United Nations Environment Programme, Nairobi, Kenya, 2013.

Velders, G. J. M., Andersen, S. O., Daniel, J. S., Fahey, D. W., and McFarland, M.: The importance of the Montreal Protocol in protecting climate, Proc. Natl. Acad. Sci., 104, 4814-4819, doi:10.1073/pnas.0610328104, 2007.

Velders, G. J. M., Fahey, D. W., Daniel, J. S., McFarland, M., and Andersen, S. O.: The large contribution of projected HFC emissions to future climate forcing, Proc. Natl. Acad. Sci., 106, 10949-10954, doi:10.1073/pnas.0902817106, 2009.

Velders, G. J. M., Ravishankara, A. R., Miller, M. K., Molina, M. J., Alcamo, J., Daniel, J. S., Fahey, D. W., Montzka, S. A., and Reimann, S.: Preserving Montreal Protocol climate benefits by limiting HFCs, Science, 335, 922-923, doi:10.1126/science.1216414, 2012. further gets added to the
Velders, G. J. M. and Daniel, J. S.: Uncertainty analysis of projections of ozone-depleting substances: mixing ratios, EESC, ODPs, and GWPs, Atmos. Chem. Phys., 14, 2757-2776, doi:10.5194/acp-14-2757-2014, 2014.

WMO: Scientific Assessment of Ozone Depletion: 2010, Global Ozone Research and Monitoring Project - Report No. 52, World Meteorological Organization, Geneva, Switzerland, 2011.

Xu, Y., Zaelke, D., Velders, G. J. M., and Ramanathan, V.: The role of HFCs in mitigating 21st century climate change, Atmos. Chem. Phys., 13, 6083-6089, 10,

http://www.atmos-chem-phys.net/13/6083/10/.5194/acp-136083-2013, 2013. 